\title{
Polarities and Dualities: East West Perspectives in Art Therapy with a Refugee Woman from Central Africa
}

\section{极性和双极 : 以东西方观点看与中非一名女性难民的艺术治疗 \\ Debra Kalmanowitz \\ Academic College of Society and the Arts (ASA), Israel}

\begin{abstract}
This article explores the dynamic interaction between Western and Eastern ideas in art therapy with Laura, a refugee woman from Central Africa. It focuses on some ideas of Qi, health and well-being; of mindfulness, energy and somatic psychology, psychobiology and trauma as it is understood in art therapy with Laura.
\end{abstract}

Keywords: Art therapy, Qi, Psychology, Refugee, Trauma

\section{摘要}

这篇文章将探索在与中非女性难民劳拉的艺术治疗中东西方观点的活跃互动。文章涉及 的议题包括"气"、保健与健康、正念、能量和躯体心理学、心理生物学和创伤以及怎样 在劳拉的艺术治疗中去理解这些议题。

\section{关键词: 艺术治疗，气，心理学，难民，创伤}

Where's the trail to Cold Mountain?

Cold Mountain? There's no clear way.

Ice, in summer, is still frozen.

Bright sun shines through thick fog.

You won't get there following me.

Your heart and mine are not the same.

If your heart was like mine,

You'd have made it, and be there!

(Hang Shan, (7-9 ${ }^{\text {th }}$ Century), Kline, 2006)

\section{Introduction}

There exists an interesting relationship between the East and the West - China and the United States specifically. Although older Chinese generations still find themselves oriented towards more traditional values and culture (namely filial piety, patriarchal family structure, nationalistic identity and an orientation towards the past and not the future) 
younger members of Chinese society love American consumerism and US culture especially music, style and fashion. Western interest in China is growing as it becomes recognized as one of the world's greatest economies and an emerging superpower which has an important role to play in international politics and trade.

China's history, philosophy, religion, beliefs and social practices are all present in its art. Chinese calligraphy and Chinese landscape paintings are art forms that stand in their own right whilst also embodying many aspects of Chinese philosophy and culture. The notions of Qi and meditative practice are central to these. Similarly, ancient Greek sculpture (3000BCE- 400CE) allows us insight into the psyche of the great early Western civilizations. It was during this period that the ancient Greeks first applied human reason to their observations of the natural world and created some of the earliest naturalistic images of human beings. This period is often credited with the birth of Western philosophy, mathematics, theatre, science and democracy (Khan, 2017, para 5).

The Eastern notions of mindfulness and Qi are ideas that have been embraced by the West -interacting with Western sensibilities and impacting both on the arts and psychology. Contemporary American artist Brice Marden has attributed some of his most famous works (beginning in the 1980s) to his fascination with Taoist philosophy and his exploration of Chinese calligraphy. In 1979 John Kabat Zinn (1990) popularized mindfulness meditation in the field of psychology (although this is not Chinese, but Buddhist in origin), through his program for the reduction of stress which was known as Mindfulness Based Stress Reduction (MBSR). Kabat Zinn's work and research have had a significant impact on contemporary psychology and the practice of mindfulness has become integral to many of the therapeutic approaches that form the Third Wave Cognitive Behavioral Therapy. These include Acceptance Commitment Therapy (ACT) (Hayes, Strosahl \& Wilson, 1999), Dialectical Behavioural Therapy (DBT) (Linehan, 1993) and Mindfulness Based Cognitive Therapy (MBCT) (Segal, Williams \& Teasdale, 2013).

This relationship, however, works both ways. Since the beginning of the $21^{\text {st }}$ century, more traditional psychotherapy practices have become increasingly popular in China. "Zhang's enthusiasm for the 'talking cure' reflects a wider surge in interest as China's citizens seek meaning beyond the quest for prosperity" (Branigan, 2014, para 4). Ethnographer Huang Hsuan-ying (who has been studying the growth of psychotherapy in China since 2007) writes:

Chinese people have been hungering and searching for something for a long time since the collapse of Maoism. Every so often there's a certain 'fever' sweeping the country...it fits into that long-term search for something that is not only material (Branigan, 2014, para 5).

Interestingly, the Western world's fascination with Eastern Philosophy seems to have originated from a similar need. While Western philosophy - inspired by the love of wisdom - is defined by its intellectual pursuit, it is through psychology and religion that individuals can find tools for coping with the challenges they face in life. Eastern philosophies, however, seem to provide ideas as well as practices for life and, like the growing importance of mindfulness in contemporary psychology, it seems that these ideas have been separated in the West from both faith and religion. 
Incorporated into cognitive models of therapy, mindfulness is considered a pragmatic method that offers a way of decreasing anxiety, depression and pain (Wylie, 2015). This differs from the traditional Eastern approach that looks for a less linear line of cause and effect and understands this to be connected to morality, spirituality and the nature of the world. Traditionally, meditation is perceived as a disciplined practice which takes years to master within a spiritual, ethical and social framework; its final aim is an increased sense of awareness, of self-knowledge, of understanding the subtleties of our existence and eventual enlightenment (Wylie, 2015).

This paper looks at the combination of both Eastern and Western ideas used in art therapy with Laura, a refugee from Central Africa. Wisdoms from both traditions have formed a vital part of her therapy. It is interesting that Laura comes not from the West or the East but from Africa. This, of course, adds a fascinating cultural complexity to the art therapy session. This will not, however, be expanded upon here as it is beyond the scope of this paper. What is pertinent is that Laura suffered greatly from events in her home country and this lead to a severely traumatic reaction to these events.

Art therapy with Laura drew on my experience as an artist, art therapist and practitioner of tai chi, Qi gong and meditation. The theories and ideas presented here relate specifically to this. This is not a research paper and does not make any objective claims at truth. It does, however, describe the reality of the therapy and expresses some of the thinking that took place during our work together over a period of almost two years.

Eastern and Western perspectives on art therapy are often represented in opposition to each other. Although there are many differences, I have found this approach to be somewhat simplistic as both are dynamic and evolving cultures. To this end, I find the parallels to be more interesting. The ideas presented here focus on these parallels as well as some of the places where philosophies diverge.

\section{Laura}

Laura, a refugee from Central Africa who eventually sought asylum in Hong Kong, was raped repeatedly, forced to watch the beheading of her parents, and - for a period of over seven years - lived in fear for her own life and for that of her children. A religious Christian, Laura placed God firmly outside of herself. She prayed every day but described that she could not feel any connection. For Laura, God was - in theory - considered a benevolent strength upon which she was supposed to draw; in practice, however, this sense of God was a strength she could not find. Laura experienced this feeling of disconnection not only to God but also to herself and her society. The concept of religion, of personal values and belief systems were fundamental to our communication during this therapeutic treatment and to Laura's art work too.

Laura perceived herself to be tainted and dirty. Her mind was full of uninvited but recurring memories and she spoke of her soul being destroyed. Day to day, she suffered from dissociations (detachment or disruption from her identity, feelings, memories, thoughts and environment) and depression. Although Laura had managed to carry on and keep her children safe, she found that, since her arrival in Hong Kong, she had simply ceased to function. In her art therapy, Laura described a litany of physical symptoms: 
she experienced fear, anxiety, pains in her head, stomach and back while, at the same time, she felt numb inside. She described herself as alive but dead.

In my work with Laura, it was most frequently the somatic symptoms that I encountered. Months of suffering from the same relentless pain had led to Laura feeling both disempowered and hopeless. Despite being desperate to overcome these symptoms, she found it difficult to affect change in face of the repetitive nature of her recurring memories, nightmares and primarily negative thoughts.

Beyond the pains in her body and the repetitive images of events, Laura could not locate emotions, thoughts or sensations in her mind or her body. When Laura's emotions were activated, she could not recognize what she was feeling. Alexithymia is the inability to verbally identify the meaning of physical sensation and muscle activation (Ogden, Minton \& Pain, p. xxii) and the implications of this for Laura were that - in attempting to survive these amorphous and threatening emotions and sensations she contracted both in her body and her mind - her rigid response led to a stasis which was powerful and all-pervasive in her life and in her therapy.

Before continuing, it is important to clarify that although refugees have lived through traumatic events and suffer from tremendous loss, most people who survive regain their equilibrium and do not need specialist help (Friedman, 2015). This, however, was not the case for Laura. While the symptoms that most disturbed Laura were deeply personal, we remember that trauma is connected not only to the individual but also to the culture too, and as such are embedded with social meaning (Kalmanowitz \& Ho, 2016 a, b). This is evident in Laura's story, but does not form the focus of this paper. East-West perspectives in therapy with Laura are reflected upon here and are presented as succinctly as possible; but, of course, clients' lives are neither succinct nor simple. Before returning to Laura, I would like to consider some of these ideas.

\section{Eastern perspective}

\subsection{Qi}

The notion of Qi is fundamental to Confucius and Taoist philosophy and to Chinese, Japanese, and Korean thinking. Some words given to the description include energy, air, breath and wind. Definitions of this idea can vary and indeed sometimes even contradict each other. This makes it a dynamic process when seeking to describe the notion in English. Most frequently, however, Qi is defined as a life force that flows through everything and implies a connection between all things. Chinese traditions tend to look towards nature to define their concepts and Qi is sometimes compared to water. Where it cannot flow freely, it stagnates; where it flows too fast, it can cause destruction.

Qi is also captured in the process of calligraphy and Chinese landscape paintings where it stands as a metaphor for the natural scenery of mountains and water for the vibrations of life itself. The making of the image and the image itself are not only about art for art's sake but represent, for the individual, the right spirit and the energy or Qi through action and metaphor. McNiff (2016) suggests “...there is no hierarchy of ch' $i$ in art and in life..." (p. 18) and that both art and life are in a continuous "reciprocal process of creative transformation" (p. 18). 


\subsection{Tai chi}

Tai chi is a martial art. The principles of Tai chi are drawn from Taoist philosophy and highlight the natural balance of things. The emphasis is on slow and balanced movement; the principles are of yielding, centering, grounding, rootedness and softness. Contemplation and reflection on nature are also fundamental to Tai Chi and are as seen in the names given to the movements - namely "White Crane Spreads Wing," "Snake Creeps Down" or "Repulse monkey". By linking movement to nature, meditation and the cultivation of Qi, the practice of Tai chi and Qi gong also emphasizes a link to the morality of life. This underlies an approach that stresses the importance of living in harmony with nature rather than in competition with it. According to Chan (2006), this is in contrast to "the Western values of striving for excellence, competition, achievement, and success of life" (p. 16).

\subsection{Health and Wellbeing}

In Chinese philosophy, yin and yang describe the idea of the interconnectedness of contrary forces and represent the complementary and interdependent nature of contradictory or opposite polarities. The contradictions exist together and are inseparable.

Health and wellbeing are connected to this notion of yin and yang. In the traditional Chinese medicine paradigm, the balance between these two opposing forces is fundamental and the correct balance between the two must be reached for harmony to be achieved. An increase in one will bring a corresponding decrease in the other, leading to an imbalance.

This connection between yin and yang represents an overall unity of things and is expressed in human form in terms of the unity of the body and the spirit. In Eastern classification, the physical, emotional and spiritual are considered indivisible while still forming distinct aspects of the same reality (Chan, 2006).

This unity and harmony exist both inside and outside the individual. In traditional Chinese medicine, health and wellbeing result from the balance of Qi between the internal aspect of the person, the external environment, nature and the universe (Chan 2006).

Here we see the broadening of the spectrum of harmony to include not only the internal balance within one person but also the interaction between the external systems and inter-relations between people and society and the natural world. All of these aspects are understood to contribute to a unified whole. Health is seen as an harmonious equilibrium between Yin and Yang, the five elements (earth, wood, water, metal and fire), the internal environment (dry, wet, hot, cold, wind, flame), external conditions (physical harm, insect bites, poison, overeating, too much sex and overwork), and the emotions (joy, sorrow, anger, worry, panic, anxiety and fear) (Yin et al., 1994) (in Chan 2006, p. 4). This connection to nature exists in art therapy thinking too. McNiff (2016) refers to art making as a "force of nature" (p. 17) and suggests a reciprocal relationship between nature and our artistic expression.

This holistic approach is similar to ecological and systematic approaches in psychology. Western classifications both acknowledge and work with the connections between different approaches. The body and the mind, (cognition, emotions, social and individual behavior) are still, however, understood to be discreet entities. When considered as a whole in traditional Chinese thinking, the body and the mind are indivisible - both impacting on and influencing each other. In this kind of thinking, somatic complaints 
cannot be separate from emotional suffering - with the flow of Qi forming one of the most important concepts in traditional Chinese medicine (Chan, 2006).

\section{Western Perspectives}

\subsection{Energy and somatic psychology}

By equating two things with each other that come from different systems, with distinct origins, and that speak two different languages, there is a chance of flattening both. At the risk of doing so, I would like to align for the reader the notions of Qi and yin and yang with the ideas of somatic psychology. As already defined above, Qi and yin and yang are broad terms with encompassing implications; however, in relation to health and well-being, they refer to the holistic approach and connection between the body, mind and spirit. The connection between the body and the mind is represented in Western thinking too.

In the 1930s, psychiatrist Wilhelm Reich noticed what he defined as 'an energetic connection' that was shared by all living beings. He called this energy Orgone. He understood this energy to exist in the atmosphere, in space and in living organisms and to be synonymous with life energy itself (Sharaf, 1983). Reich's attention to the body, energy, movement and his notion of muscular armour have shaped body psychology today. Alexander Lowen (1994), a student and patient of Reich's, built on Reich's ideas to develop Bioenergetic Analysis - a form of analysis which connected muscular tension to mental health and was based on the idea that there is continuity between the body and the mind and that emotional blocks reveal themselves in the body (Lowen, 1994). Bioenergetics and other body therapies or somatic therapies like Gestalt Therapy (Fagan \& Sheperd, 1970), Hakomi Method (Kurtz,1990) and Sensorimotor Therapy (Ogden, Minton \& Pain, 2006) all draw on this same idea.

\section{2. 'Top-down' or 'bottom up'}

The psychobiology of trauma (van der Kolk, 1987, 2014) has challenged our notions of the effectiveness of pure psychotherapy in the field and has forced us to see the connection between the mind and body in trauma. Descriptions of the hierarchical organization of the brain (Ledoux, 2002, 1996) have allowed us to understand that there are "two distinct directions of processing information - from the "top-down" or the "bottom-up" and "the interplay between them holds significant implications for the treatment of trauma (Ledoux, 2002)" (in Ogden, Pain \& Fisher, 2006, p. 6). Studies show that the front part of the brain (which impacts executive functioning) becomes impaired in trauma (van der Kolk, 2014).

At the top of the hierarchy is cognitive functioning and at the lower level is the limbic system and sensorimotor experience. In the traumatized person, the intensity of emotions and overwhelming sensorimotor reactions can disrupt the individual's cognitive capacity. This is described by Ledoux (2002) as "bottom-up hijacking".

The imprint of trauma doesn't "sit" in the verbal, understanding, part of the brain, but in much deeper regions - amygdala, hippocampus, hypothalamus, brain stem-which are only marginally affected by thinking and cognition. 
These studies showed that people process their trauma from the bottom up-body to mind - not top down. But if trauma is situated in these subcortical areas, "then to do effective therapy, we need to do things that change the way people regulate these core functions, which probably can't be done by words and language alone." (van der Kolk in Wylie, 2004)

The introduction of Tai chi, Qi gong and mindfulness meditation relates in part to "bottom-up hijacking" by engaging the body in movement, breath, fluidity, meditative and present focus. Despite the prescribed forms of Tai chi and Qi gong, the overriding principle is to move with nature, not against it. Tai chi masters teach us to initiate movement from the dantian (energy centre); to yield and not resist. By choosing to go with the movement as opposed to resisting it, we can mobilize the energy that has formed from cooperation with nature. Let us now return to looking at some of the aspects of art therapy with Laura.

\section{Return to Laura}

We left Laura, above, stuck - caught literally in a frozen body and in ruminative negative thought patterns. These patterns had come to define her personal narratives; they continued to negatively reinforce her actions and her day-to-day functioning and they dominated her sense of identity. Ogden, Minton \& Pain (2006) write that traumatized people can develop "inflexible, maladaptive interpretations of the trauma or other life experiences" (p. 9) which then forms inadvertent, generalized thoughts that are negative and erroneous. This way of describing the repetitive, circular thinking is compatible with the way in which it is described in Cognitive Behavioural Therapy (CBT) (Beck, 2008).

Maladaptive emotions and cognitions are also referred to in the Buddhist tradition as one of the targets of mindfulness meditation. The Theravada Buddhist tradition defines the aims of meditation practice as developing awareness and a stable mind (a clear mind, able to observe itself and examine itself, unaffected by volatility of emotions) so as to lead to the end of maladaptive emotions and cognitive impurities. Such impurities include feelings such as desire, hatred, jealousy, worry and the cultivation of awareness, wisdom and virtuous qualities which allow us to behave and think without the distortions or biases inherent in our thoughts and perceptions (Collins, 1982).

Theravada Buddhists connect thoughts with action paralleling the findings of Ogden, Minton \& Pain (2006) who connect each one of our thoughts to mental actions, sensorimotor reactions and emotions (Ogden, Minton \& Pain p. 9).

In terms of Chinese philosophy, this sense of stuck-ness/stasis points to the theories of yin and yang and to an internal imbalance and an obstruction of the flow of chi. Frozen by terror, immobilized by uninvited memories, Laura had literally become immobile in her body. She could not move her neck or shoulders and her torso had become a solid block. She felt like she could barely breathe.

For many months, Laura recalled images and memories of rape, torture, death and destruction. Her eyes lowered, she slouched physically and her energy was sluggish. There seemed to be no entry point for communication or interaction. I wondered if I could ever reach her. It seemed that nothing could come in and nothing could go out. 


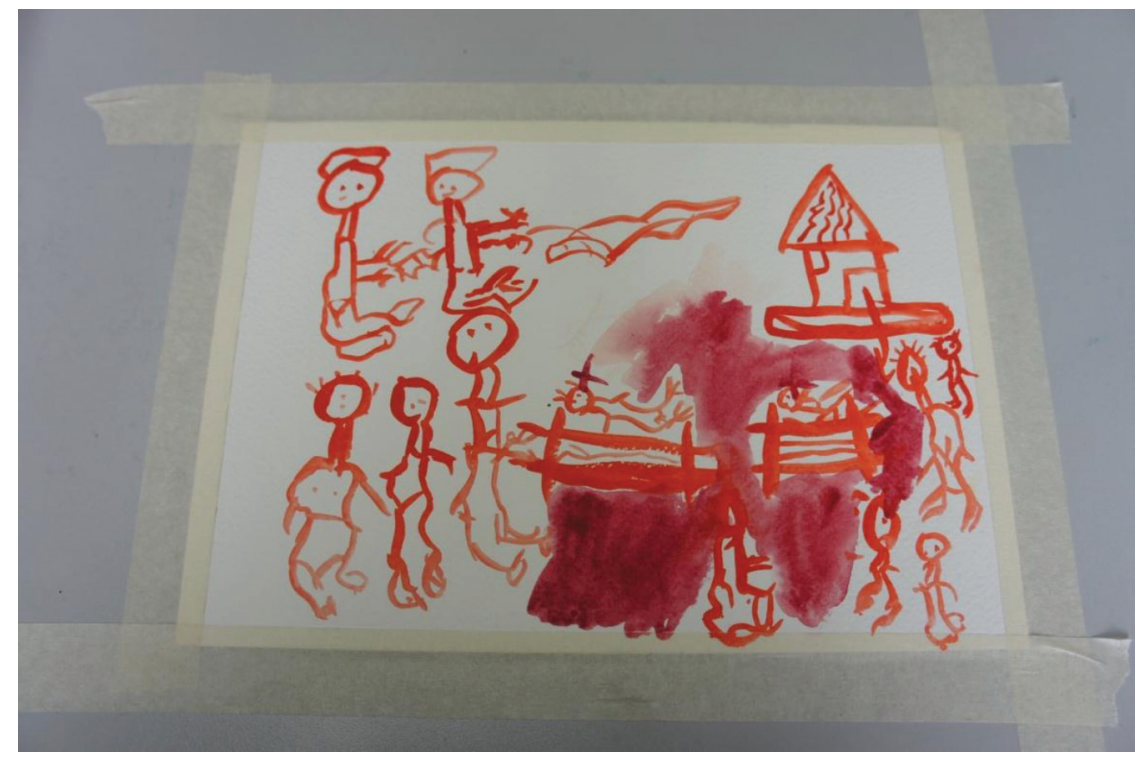

FIGURE 1 | Laura memories of her home under attack

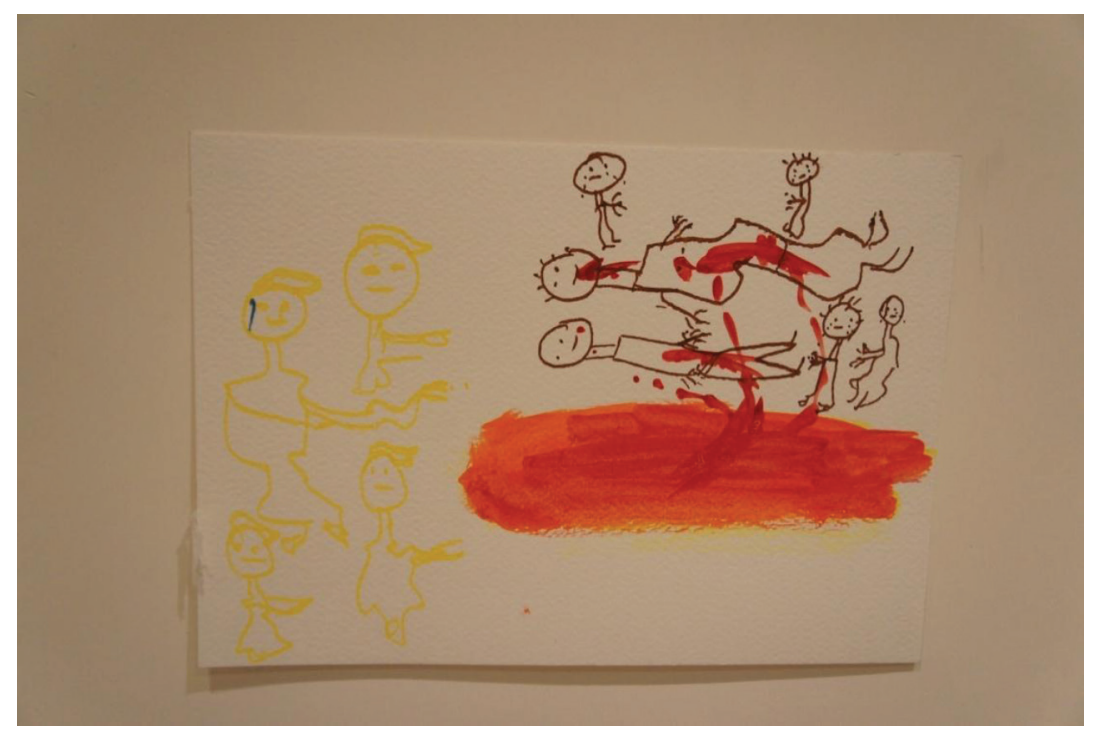

FIGURE 2 | Laura memories of injury and death

While Laura may have survived initially by constricting her movement (both physically and mentally), this no longer served her; in fact it did the exact opposite. Laura's compulsive need to draw and redraw the traumatic events had long passed the stage of telling her story. It caused her great distress and led her to forget where she was as she relived the experiences again and again.

Laura's image-making perpetuated the circling of the same horrific events in spite of her desire to end her suffering. Equal to this however, was her terror of getting up 
from the chair. After some months in art therapy, Laura agreed to breathe with me. I introduced some very basic mindfulness breathing exercises alongside a mindful focus on sound and body sensations.

In our sessions, I tried to encourage Laura to abandon her position on the chair - so leaving less time for the art and more and more for the mindfulness exercises with a focus on the present moment and on a compassionate, non-judgmental and forgiving attitude towards herself and others. Together we did a combination of mindfulness meditation, walking meditation, Qi gong and tai chi exercises, beginning with breath (with which she was already familiar). These slow and gentle movements exhausted Laura and she frequently had to retreat to the edge of her chair to rest. Despite this, however, she agreed to undertake a sequence of exercises I had suggested she complete during the days in between our sessions. These exercises would be carried out both morning and night at home. Many months passed during which we moved together, following a traditional form, (tai chi, Qi gong), but not in a prescribed way; this allowed Laura to interpret these movements as she wished. Slowly she gained more mobility in her torso and more movement in her neck. Slowly, she agreed to join me in printmaking.

Choosing a material she had not used before allowed Laura to move back to the page and this time she was making marks on large sheets of paper. Creating monoprints meant making sweeping gestures on a sheet of glass, and then using rubbing movements on the page to allow for the image to be imprinted. Rubbing the large sheets created a different type of movement, and the way in which the materials were set up demanded that Laura stand while making them. In printmaking, the marks were made indirectly and the shapes that were made in the ink were not solidified until the paper was placed on top - so creating a veil between the ink and the movement. This allowed Laura to be

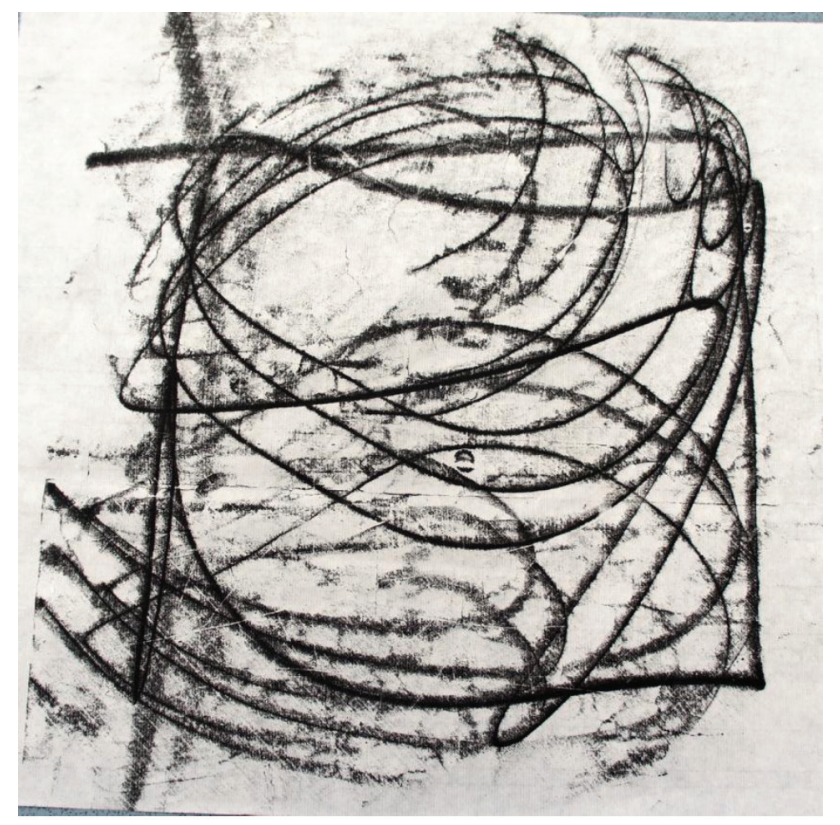

FIGURE 3 | Monoprint 
present in the room - and with what she was feeling - and produced images that were not the compulsive drawings of the months before.

The movement fundamental to this process reminded Laura to breathe and she began to speak about her breath as a new-found ability. Her husband reported that she was having bursts of returning to life and spent less time on the sofa. The social workers also reported that Laura was more engaged and spent less time staring into space. It was as if they were seeing Laura for the first time. She was managing to maintain eye contact and even volunteering to help.

\section{Polarities and Dualities}

The symbols of yin and yang give us a visual understanding of the ebb and flow of energy and the connectedness of polarities. Maciocia (2009) writes that according to Chinese philosophy "...the spirit, soul and body are nothing but different states of "condensation and aggregation of qi" (p. 4) and that the "symbiosis" (p. 5) or unity of the two polarities (in this case the body and the mind), in a circular direction is understood to be an "organismic" (p. 5) process - both of which need each other (Maciocia, 2009). Maciocia (2009) reminds us that "The word "spirit" means "breath" and comes from spiritus, the Latin rendering..." (p. 2) of the word. The Greeks viewed spirit as a "refined form of matter" (Maciocia, p. 2) and the crystallization of the duality and polar opposites as represented in a more linear fashion which arose with the Christian religion with the division between "a subtle non-material "spirit" and the material body becoming firmly established” (Maciocia, 2009, p. 2).

When Laura first came to art therapy, she lived a reality of duality. She described herself as third generation Christian. Religion and God were important to her identity. However, as a result of feeling contaminated and adulterated, Laura's connection with God had become severed - as had her connection to her body, emotions and thoughts. Laura attached the loss of connection to God to the death of her soul. Laura's understanding of soul was connected to her religious beliefs and laden with the meaning given to it by Christian scripture; together with this, Laura described her loss of soul as the loss life within her.

This former perception of her spiritual self, along with her now physical pain and an inability to recall any good memories from her childhood or adulthood (before the trauma), led Laura to perceive herself as ill with very little likelihood of healing. Her split view represented not only her view of herself but also that of the broken society from which she had come.

Our western thinking tends to place our different parts at two ends of a spectrum divided rather than all part of one whole; the arts and science, imagination and logic, internal and external, good and bad, them and us, safe and unsafe. Papadopolous (2005) reminds us that the ways in which we relate to violence are also divided and polarized.

Violence too leaves little margin for grey areas and tends to make us see things in terms of 'black' and 'white'. This is understandable. When exposed to violence, our primary response is self-preservation and our impulse would be to choose the safest option in the shortest possible time (p. 37) 
We identify immediately with our own pain and suffering or that of a victim and this creates a pressure - within both us and them - "demanding an instant cessation of the pain. This overwhelming pain, (theirs and ours) threatens to disrupt all external and internal order and is difficult to tolerate" (Papadopoulos, in Kalmanowitz \& Lloyd, 2005, p. 37).

Once violence erupts, this schism becomes complete and, in so doing, contradictions and internal conflicts are resolved, not only at an individual and community level but at a state level as well (Papadopoulos, 2005). Individuals and societies lose their ambivalence and become one way or another. It is this singular position within which our clients, and often we ourselves, are ensconced. Entrenched in our ways of viewing the world, we too need help to see things differently and to make new connections.

We know that this dual position directly impacts our ability to imagine; McNiff (1999) writes "As soon as the mind becomes fixated on a singular position, it loses the ability to see the creative interplay and benefit from it" (p. 8). This creative interplay is the place we art therapists try to hold in the understanding that this is fundamental to change.

The combination of art making, movement and mindfulness meditation in art therapy sessions allowed Laura to just be with the doing. Here, doing refers to engagement in process - in the direct experience of activity or inactivity - thus moving away from these dualities. Laura was able to feel herself in the movement of Tai chi and Qi gong as well as in her art making and this engagement allowed her, at the same time, to be with the sadness and suffering, to connect to her own strength (both personal and cultural) as well as, in her own words, to rekindle "connection to her soul". Levine (2015) and McNiff (2016) suggest that the word Qi is equivalent to soul and that "If a work or practice does not embody soul, it has no power to move us. It is lifeless and inert." (Levine 2015 p. 23)

\section{Conclusion}

In Laura's therapy Eastern and Western thinking came together. Integrating these two philosophies allowed us to address her difficulties and concerns united by our relationship to suffering and well being.

A combination of Eastern and Western understanding of the psyche facilitated a model of work to which Laura responded. Engagement of the body and the art making (mark making and imagination) allowed her to gain awareness - to build a sense of control and regulation - and to enable a slow but significant ability to locate herself in the present time as well as developing the potential to reconnect herself with the natural world and with her God. In her early stages of work, traditional art therapy notions of expression through art seemed to trigger Laura into a state of dissociation: a more holistic approach to process and materials alongside an attitude of acceptance (common to both approaches) helped Laura to connect and collect her fragmented parts. Although not illustrated here, continued work with Laura led to her return to the art making and art process and to the use of materials in very different ways.

I have laid out the importance of linking to a whole in working in this context. Not only do we try to give place to the sensory and physiological experience of trauma, but 
we try to create a space to link the individual to their personal sense of morality, to the group, the society, the culture and the natural world through being in the present with an openness and acceptance. As difficult and slow as it can be when a person is frozen (as Laura was) working through this process with the body and imagination seems to offer a key to moving from duality (from which Laura was forced to detach) to polarity (experiencing the connections between her disconnected parts) and the flow between them.

There are no easy answers to working with trauma, to mending body-mind splits or the splits in our society. I am however, convinced that the methods used are more productive when we engage in the inter-relations between the multiple aspects of our being. Engaging with the former facilitates an understanding of many complex and subtle issues and allows for deep exchange. Han Shan's verse from his poem "Cold Mountain" with which I began this paper suggests that in order for us to understand our world we need to travel our own path. Assumptions of purely linear relationships belong to a dualistic way of understanding the world and can be seen as an oversimplification (Lee, $\mathrm{Ng}$, Leung, Chan, 2009); they prevent us from reaching exactly those sources of strength and support we seek. Dealing with the body and the mind - with social and natural structures simultaneously - may lead us into the area of nonlinear relationships. 'There's no clear way', writes Han Shan; yet through a willingness to connect all aspects of our reality, a way may become clear.

\section{About the Author}

Debra KALMANOWITZ, PhD, HCPC, BAAT reg. artist and art-therapist has worked with trauma, political violence, and social change, globally as well as with refugees and torture survivors in London and Hong Kong. She is a Professional Advisor for an International NGO (IsraAid) working in Liberia - focused on gender based violence (GBV) and the Clinical Lead for a London based NGO (Refugee Trauma InitiativeRTI) working in Greece's refugee crisis. She teaches at the Academic College of Society and the Arts (ASA-Israel). She is the co-author of several books including the edited book Art Therapy in Asia: To the Bone or Wrapped in Silk.

\section{References}

Beck, A.T. (2008, Aug). The evolution of the cognitive model of depression and its neurobiological correlates. American Journal of Psychiatry, 165(8), 969-77 doi: 10.1176/appi.ajp.2008.08050721.

Branigan, T. (2014). It's good to talk: China opens up to psychotherapy. Retrieved from https:/www. theguardian.com/world/2014/sep/03/china-psychiatrists-talking-therapy-counselling.

Chan, C. C. (2006). An eastern body-mind-spirit approach. A training manual with one second techniques. Hong Kong, China: The University of Hong Kong.

Collins, S (1982). Selfless persons. Imagery and thought in Theravada Buddhism (p. viii). Cambridge, UK: Cambridge University Press.

Fagan, J. \& Shepherd, I. L. (1970) Gestalt therapy now: Theory, techniques, applications. Oxford, England: Science \& Behavior Books. Gestalt Therapy now.

Friedman, M. J. (2015, August 17). PTSD National centre for PTSD. PTSD history and overview. Retrieved from http://www.ptsd.va.gov/professional/PTSD-overview/ptsd-overview.asp.

Hayes, C.S., Strosahl, K., \& Wilson, K.G. (1999). Acceptance and Commitment Therapy. New York: Guildford Press. 
Kabat Zinn, J. (1990). Full catastrophe living. Using the wisdom of your body and mind to face stress, pain, and illness. New York, NY: Bantam Dell Books.

Kalmanowitz, D. \& Lloyd, B. (2005). Art therapy and political violence. With art without illusion. London, New York: Routledge.

Kalmanowitz, D., Ho, R.T.H. (2016a, July). Out of our mind. Art therapy and mindfulness with a refugees, political violence and trauma. The Arts in Psychotherapy, 49, 57-65.

Kalmanowitz, D., Ho, R.T.H. (2016b). Art Therapy and Mindfulness with Survivors of Political Violence: A Qualitative Study. Psychological Trauma: Theory, Research, Practice, and Policy.

Khan Academy. (2017). A brief history of western culture. Retrieved from https://www.khanacademy.org/ humanities/ap-art-history/cultures-religions-ap-arthistory/a/a-brief-history-of-western-culture.

Kline, A.S. (2006). Words from Cold Mountain. Twenty-seven poems by Han-shan. Retrieved from http:// www.poetryintranslation.com/PITBR/Chinese/HanShan.htm

Kurtz, R. (1990). Body-centered psychotherapy: The Hakomi Method: The integrated use of mindfulness, nonviolence, and the body. Mendocino, CA: Life Rhythms.

Lee, M.Y., Ng, S.M., Leung, P.P.Y. \& Chan, C.L.W. (2009). Integrative body-mind-spirit social work. An empirically based approach to assessment and treatment. Oxford: Oxford University Press.

Ledoux, J.E. (2002). Synaptic self: How brains become who we are. New York, NY: Viking.

LeDoux, J. (1996). The emotional brain: The mysterious underpinnings of emotional life. New York: Simon \& Schuster.

Levine, S. (2015). The Tao of poiesis: Expressive arts therapy and the Taoist philosophy. Creative Arts, Education and Therapy: Eastern and Western Perspectives, (1) 1, 15-25.

Linehan, M.M. (1993). Cognitive-Behavioural Treatment of Borderline personality disorder. New York: Guilford Press.

Lowen, A. (1994). Bioenergetics: The revolutionary therapy that uses the language of the body to heal the problems of the mind (Compass). Arkana, USA: Penguin Books.

Maciocia, G. (2009). The psyche in Chinese medicine. Treatment of emotional disharmonies with acupuncture and Chinese herbs. Edinburgh, London: Churchill Livingston Elsevier.

McNiff, S. (2016). Ch'i and Artistic Expression: An East Asian Worldview that Fits the Creative Process Everywhere. Creative Arts Education and Therapy: Eastern and Western Perspectives, 2 (2), 12-20.

McNiff, S. (1999). Cultivating imagination, Poeisis: A Journal of the Arts and Communication, 1.

Ogden, P., Minton, K., Pain, C. (2006). Trauma and the body. A sensorimotor approach to psychotherapy. New York, London: W.W. Norton \& Company.

Ogden, P., Pain, C., Fisher, J. (2006). A sensorimotor approach to the treatment of trauma and dissociation, Psychiatric Clinics of North America, 29, 263-279.

Papadopolous, R. (2005) in Kalmanowitz, D \& Lloyd, B. (2005) Art therapy and political violence. With art without illusion. London, New York: Routledge.

Sharaf, M. (1983). Fury on earth. A biography of Wilhelm Reich. New York, NY. St. Martin's Press/Marek.

Segal, Z., Williams, J.M.G. \& Teasdale, J. (2013). Mindfulness-based cognitive therapy for depression. A new approach for preventing relapse. New York: Guildford Press.

van der Kolk., B. (1987). Psychological trauma. Washington: American Psychiatric Press Inc.

van der Kolk, B. (2014). The body keeps the score: Brain, mind, and body in the healing of trauma. New York, NY: Penguin Books.

Wylie, M. S. (2004). The limits of talk. Psychotherapy Networker, 28(1), 30-36.

Wylie, M. S. (2015, Jan 29) How the mindfulness movement went mainstream and the backlash that came with it. Meditation is more complex than some people realized. Alternet. Retrieved from http:// www.alternet.org/personal-health/how-mindfulness-movement-went-mainstream-and-backlash-came-it 